\title{
Sentido e limites do diagnóstico diferencial entre psicoses endógenas e exógenas
}

\author{
Guilherme Peres Messas ${ }^{1}$
}

\section{Resumo}

Examina-se neste artigo a pertinência do diagnóstico diferencial entre psicoses endógenas e exógenas na psicopatologia fenomenológica. Após identificar os pressupostos dualistas que sustentam historicamente a distinção, o autor apresenta em linhas gerais como uma ontologia monista entende o tema das relações de conexão entre fenômenos. Para que se decifre a relação de conexão na psicopatologia fenomenológica é necessária a substituição da noção de causa ou de motivo - referentes a um dualismo latente - pela de origem. A origem, por sua vez, é determinada pelo sentido da estrutura da consciência. Assim, endogeneidade e exogeneidade passam a só poder ser definidas a partir da interioridade desta estrutura. Uma psicose classifica-se como endógena quando houver i. desestruturação da articulação primordial da estrutura, ii. impedimento da restauração dessa articulação e iii. autonomização de zonas parciais da estrutura. Por outro lado, todo fenômeno psicótico não agudo cuja origem se der fora da região de articulação primordial da estrutura da consciência com o mundo será exógeno. Os limites e intersecções destes diagnósticos também são examinados.

Palavras-chave: Psicoses endógenas; Psicoses exógenas; Diagnóstico diferencial; Origem de psicoses.

\footnotetext{
${ }^{1}$ Médico psiquiatra, mestre em Medicina e doutor em Psiquiatria pela Universidade de São Paulo. Membro Fundador e Presidente da Sociedade Brasileira de Psicopatologia FenômenoEstrutural. Coordenador do Curso de Especialização em Psicopatologia Fenomenológica da Faculdade de Ciências Médicas da Santa Casa de São Paulo. Membro da Câmara Técnica do Conselho Regional de Medicina do Estado de São Paulo. Email: messas@fenomenoestrutural.com.br
} 


\title{
Meaning and limits of the differential diagnosis between endogenous and exogenous psychoses
}

\begin{abstract}
It is examined in this article the pertinence of the differential diagnosis between endogenous and exogenous psychoses, from a phenomenological point of view. Initially the author identifies the historical dualistic foundations of this distinction and then presents how a monistic ontology understands the theme of connection between phenomena. In order to disentangle the relations of connection in the phenomenological psychopathology it is necessary to replace the notions of cause and motivation - both referring to a dualistic point of view - by the notion of origin. The origin is determined by the meaning of the structure of the consciousness. Therefore, endogeneity and exogeneity may only be defined from the very innerness of this structure. A psychosis can be classified as endogenous if there is i. destruction of the primordial articulation of the structure, ii. hindering of resuming this articulation, and iii. autonomous actions of partial regions of the structure. Nevertheless, every non acute psychosis whose origin is external to the region of primordial articulation of the structure is exogenous. The limits and intertwining of these diagnoses are examined as well.
\end{abstract}

Keywords: Endogenous psychoses; Exogenous psychoses; Differential diagnosis; Origin of psychoses.

Toda grade de categorias que uma atividade prática adota, tanto para sua aplicação direta como para configurar as ciências que lhe correspondem, revela os pressupostos de interesses epistemológicos que sustentam essa prática. As categorias são os instrumentos para o acesso a um mundo e, portanto, já trazem na sua própria escolha e design essa constituição prévia de mundo, em geral de modo tácito. As mudanças de concepção de mundo levariam a mudanças, seja na construção de categorias, seja no peso relativo de cada uma delas na economia global da atividade prática clínica ou científica. De hábito, na atividade prática, mais ligada às tradições e ao uso individualizado das suas técnicas, as mudanças tendem a ser mais lentas e mesclas de períodos diversos em termos de visão de mundo tendem a ocorrer. $\mathrm{Na}$ vertente teórica, passível de receber um tratamento consensual, as visões de mundo surgem de 
modo mais homogêneo e as misturas de épocas e concepções tendem a ser evitadas.

Na psiquiatria, como prática que é fundamentalmente, mas não podendo prescindir de um substrato teórico e científico, essa ocorrência surge de modo bastante nítido por meio da observação dos conceitos de psicose endógena e exógena. A psiquiatria dita consensual, consolidada pela noção de diagnóstico operacional, recusa essas categorias trazidas da tradição psicopatológica de língua alemã, enfatizando em sua arrolagem de diagnósticos as síndromes definidas em termos de sinais, sintomas e evolução. A única exceção é a categoria de psicose reativa, que também era cara à psicopatologia tradicional de língua alemã. No entanto, no cotidiano da clínica, não raramente se vê o uso consagrado dessa diferenciação capital entre endógena e exógena para uma psicose, como dois grandes grupos divididos pela origem da patologia. Se "desde dentro" de algo, é endógena, se "de fora", exógena. O pressuposto definidor desses conceitos é a busca das condições de gênese das psicoses. Subsidiariamente, o emprego de reativa para qualificar uma psicose é também bastante frequente. $\mathrm{O}$ objetivo deste artigo é examinar qual o fundamento ontológico e epistemológico dessa diferenciação, postulando motivos pelas quais ela é abandonada no operacionalismo e, por fim, identificar dentro de que limites, na perspectiva fenomenológica de psiquiatria, ela pode ser fecunda.

\section{O dualismo ontológico}

Não é o caso aqui de um retrato histórico detalhado do nascimento e evolução do emprego dos termos. Não exatamente pela escassez de espaço, mas pelo fato de que basta o exame geral de seus pressupostos para que a visão de mundo que os sustenta se revele. Basta-nos citar que foi Moebius, no final do século XIX, que propôs a divisão das psicoses entre endógenas e exógenas, sendo seguido por grande parte dos autores clássicos, como Kraepelin ou mesmo Jaspers. O interesse fundamental dessa divisão é o reconhecimento da suposta causa pontual da psicose: endógena significando uma causa "interna" à mente e exógena "externa", notadamente creditada ao corpo subjacente à mente. Bonhoeffer (1912) defende, inclusive, por meio da sua reação exógena aguda, uma inespecificidade de reação do organismo diante da agressão exógena. A divisão endógena-exógena ficaria restrita, assim, ao campo daquilo que não conseguiríamos imputar por ora ao cérebro. Com o avanço científico e a atribuição segura das diversas patologias ao cérebro, poderíamos gradualmente abandonar a divisão e mesmo a psicopatologia como ciência autônoma (Schneider, 2007). 
Por outro lado, tudo aquilo que não pudesse ser jamais reduzido ao cérebro e fosse verificadamente devido à ação de situações estressantes sobre determinadas fragilidades constitucionais - e não constituiria uma doença mental propriamente dita - receberia o qualificativo de reativo.

Conduzida dessa maneira, a noção de psicose endógena sempre recebeu um significado negativo ou nebuloso, dependente exclusivamente do estado da arte da ciência biológica. Negativo, no sentido de ser aquilo que não sabemos e nebuloso por indicar algo de influência hereditária ainda indeterminada. A noção de psicose endógena permaneceu como um estorvo na psiquiatria, para usarmos as palavras de Schneider (2007). Estorvo a ser banido com o avanço da psiquiatria e de suas ciências básicas.

Mas não apenas o ponto de ataque causal balizou o entendimento discriminatório entre psicose endógena e exógena. Também a natureza das patologias parecia ser diversa. As psicoses endógenas, as psiquiátricas propriamente ditas, apresentariam uma tipicidade de formas e curso que as distinguiriam das exógenas, mais inespecíficas ou específicas em relação à sua fisiopatologia determinada. Assim se dividiu, com Jaspers (1997), o grupo das psicoses endógenas em esquizofrenia, psicose maníaco-depressiva e as epilépticas.

De certa maneira, a divisão psicose endógena-exógena acaba por ser fundamentalmente o decalque da diferença global entre um grupo de doenças com uma causa biológica estabelecida e outro com apenas uma suposta causa biológica. É uma divisão de espécie e não de gênero.

Jaspers e, posteriormente, Schneider apuram essa divisão - sem, entretanto, alterar seus baluartes -, alçando-a ao contraste entre compreensível e incompreensível. Compreensíveis são os transtornos que podem ser derivados dos significados da personalidade adoecida e incompreensíveis são os que não dependem desse estilo básico da personalidade para surgir, sendo, novamente, remanejados ao corpo (Schneider, 1953). Por essa perspectiva, há uma identificação entre os transtornos endógenos e exógenos, à medida que ambos seriam incompreensíveis, ou seja, não derivariam de características da personalidade histórica. Com essa renomeação, permite-se, por outro lado, uma maior complexidade na abordagem diagnóstica das doenças mentais, posto que se torna possível a inclusão de elementos de incompreensividade em todos os transtornos compreensíveis e vice-versa. Ou seja, em toda condição reativa há sempre algo, digamos, biológico, como ponto de vulnerabilidade e, reversamente, em toda doença, endógena ou somática, é necessária alguma compreensão de ordem "psicológica". No entanto, os pressupostos ontológicos ainda permanecem os mesmos. Façamos uma descrição de dois deles. 
Para que faça sentido uma distinção entre exógeno, endógeno e entre ambos e o campo do reativo têm-se como condição de possibilidade que corpo e mente possam ser totalmente separados ou que doença e estrutura da consciência possam ser completamente independentes (assim como forma e conteúdo), ou seja, que haja um dualismo ontológico. Isso seria possível exatamente se não houvessem as tais psicoses endógenas ou se o uso do termo pudesse ser incontroverso. A existência delas comprova que os pressupostos epistemológicos dualistas não são suficientes para abranger de modo lógico a totalidade dos conceitos da psiquiatria. Enquanto eles se mantiverem, teremos de nos curvar ao aspecto criptógeno (Tellenbach, 1983) das psicoses endógenas.

O segundo pressuposto do entendimento dualista é o que poderíamos chamar de generalização da noção de causalidade, ou seja, a assunção de que o estabelecimento de relações de causalidade possam se dar de maneira a não se considerar o caso clínico individual. Esse pressuposto já é combatido na época clássica por Eugen Bleuler, pavimentando terreno para que alguns de seus discípulos pudessem desenvolver um caminho alternativo rumo a uma ontologia diversa. Cito Bleuler (1983, p. 135):

Uma noxa recebe seu significado apenas em razão da personalidade que é assestada. Raramente ela desacompanhada é responsável pela causa do quadro de um transtorno mental... a investigação da origem de um transtorno psíquico pode apenas de modo restrito obter sucesso através de um entendimento impessoal da doença. Ela deve aprofundar-se no destino pessoal, individual da vida do doente.

Com essas palavras podemos constatar como a psiquiatria clássica, da qual faz parte Eugen Bleuler, embora não tenha encontrado alguma solução convincente para o problema das psicoses endógenas, recusou-se a apenas negar o problema, mantendo, mesmo que inadvertidamente, a tensão de seu modelo ontológico cada vez que mencionava a endogeneidade.

\section{A antecipação histórica do operacionalismo}

Podemos aqui postular que o arrefecimento do uso dos adjetivos endógeno-exógeno no operacionalismo ${ }^{2}$ vem, acima de tudo, de uma espécie de antecipação histórica do sucesso do dualismo ontológico. Como não se

2 Defino operacionalismo como a construção de critérios diagnósticos sintomatológicos e descritivos em psicopatologia, voltados unicamente a uma função "operacional", ou seja, à pesquisa e confiabilidade científicas (Parnas \& Bovet, 1995). 
identifica alguma solução simples para a região das endogeneidades, e esta se liga diretamente ao insucesso da psiquiatria somática em absorver para si todo o campo das causas das doenças e transtornos mentais, resolve-se, por um golpe de caneta, entronizar o dualismo como estratégia vencedora. $\mathrm{O}$ método para a obtenção dessa vitória foi a exclusão dos termos que denunciavam sua fraqueza. Decide-se que o dualismo é vencedor e relega-se ao ostracismo as categorias que lhe incomodam. Pela mesma lógica, podemos dizer que os conceitos do setor endógeno se preservam no cotidiano clínico porque neste, diante dos pacientes, não se pode tomar como dada a suposta vitória incontestável do dualismo.

\section{As produções do monismo}

Os autores clássicos de opção ontológica monista, como Kretschmer, Binswanger, Minkowsi (em obras a serem citadas abaixo) e toda a corrente fenomenológica, não puderam passar ao largo do problema da diversidade de origens das psicoses. Suas psicopatologias, ditas estruturalistas, concebem a consciência e seus problemas como fruto de uma relação primordial, inseparável, entre polo egoico e polo mundano, para a qual a adjetivação dual endógeno-exógeno não pode ser, a princípio, desconsiderada. Assim, há que se determinar um constituinte estrutural fundamental que justifique e coordene todos os achados da clínica da personalidade, do Dasein ou da estrutura vivida (respectivamente, os conceitos empregados pelos autores) entendendo-os não como unidades separadas, passíveis de descrições sindrômicas, mas polos ou tendências ligadas a uma estrutura geral organizadora. Para que se decifre a relação de conexão entre dois fenômenos é necessária a substituição da noção de causa ou de motivo - referentes a um dualismo latente - pela de origem. Encampando o termo bleuleriano, pode-se dizer que o exame das origens leva em consideração, simultaneamente, o estilo particular de noxa atuando sobre uma estrutura específica de consciência, mais a sedimentação dessas experiências sobre o tempo biográfico. Importante ressaltar que essa concepção de patologia não se restringe à psiquiatria. A gigantesca obra de Kurt Goldstein (1951), por exemplo, a aplica à afasia dos lesados de guerra e Buytendijk (1967) à fisiologia geral. Três breves exemplos valem mais do que a definição (exemplos que ainda não levarão em consideração, em nome da simplicidade, as sedimentações pessoais; ficaremos na região da tipicidade de personalidade, um passo aquém, portanto, do postulado de Bleuler).

Tipo melancólico de Tellenbach. Definido como uma estrutura global de inserção no mundo na qual a ordem e o dever são a razão de ser (op.cit.). 
Consequentemente, a desordem e a negligência com o dever são possíveis pontos de origem da psicose melancólica. No entanto, num modelo monista, essas duas situações devem ser tomadas em um sentido fortíssimo e amplo. Por exemplo, desordem não contempla apenas uma desordem, digamos, psicológica, mas também contemplaria um desarranjo temporário das forças vitais do organismo, como nas mudanças de estação, dos ciclos, como sonovigília ou das funções do corpo, como uma doença atando o paciente ao leito. Todas as condições, do polo material do mundo, do polo interpessoal ou do polo egoico, seriam suficientes para deflagrar uma patologia.

Tipo sensitivo de Kretschmer. A sensibilidade extrema do eu diante dos ditames éticos, sua intolerável porosidade em relação ao mundo interpessoal neste aspecto marcam essa estrutura (Kretschmer, 1975). A polaridade eumundo interpessoal relacionada ao olhar dos pares é a mais relevante para o sensitivo, ou melhor dizendo, é demasiadamente relevante, fazendo com que situações ligadas à vergonhosa insuficiência diante do julgamento do outro possam detonar patologias de qualidade psicótica, em geral, persecutórias ou obsessivas-delirantes. A materialidade do mundo em geral é reduzida às suas expressões inter-humanas, deixando de ser um estofo de especial significância para sustentação do eu.

Tipo sensorial de Minkowska. A característica primordial desse tipo é a excessiva aproximação - ou mesmo fusão - com o mundo (Minkowski, 1999). Desdobra-se, na polaridade interpessoal, na adesividade relacional extrema; no polo egoico, na permanência temática e incapacidade de fluência de modo a parecer prolixo e extenuante, e, no polo material, na sensorialidade da matéria do mundo, na plasticidade extrema das experiências. O sentido da estrutura é dado pela permanência sobre o que está dado e pela baixa capacidade de modificação ou afastamento. Para essa estrutura, aquilo que move suas bases de modo súbito pode ser o gatilho para uma irrupção psicótica: uma ruptura violenta em relação íntima (as antigas psicoses histéricas), a intensificação súbita da materialidade do mundo, como se dá, por exemplo, na produção de crises convulsivas frente a estressantes luminosos.

Tomando esses exemplos, temos que uma característica fundamental da estrutura vivida, que se desdobra nas várias polaridades constituintes do eu, é o fator decisivo que recorta aquilo que é relevante para a consciência. Esse estilo da estrutura vivida predominante ao longo da história da vida e em relação ao qual dificilmente conseguimos identificar uma origem nítida e isolada somática ou biográfica é entendido como o sentido da estrutura da consciência. Será esse sentido que define o campo do que é compreensível. Assim, para nos 
mantermos nos exemplos acima, será compreensível que o tipo melancólico adoeça a partir de situações nas quais sinta culpa ou incapacidade de controlar as desordens da vida; será compreensível que o tipo sensorial inicie uma patologia a partir de uma situação na qual lhe seja exigida uma plasticidade que não lhe é possível; e será compreensível que o tipo sensitivo possa entrar em estado patológico caso efetivamente se prenda a uma situação na qual os olhares alheios estejam voltados a ele.

Essa compreensividade, definida pela articulação do eu com o mundo compreendendo todas as dimensões da experiência humana consciente - define o campo daqulo que é endógeno: tudo que se gera na consciência levando em consideração essa articulação primordial será endógeno. Portanto, a endogeneidade só pode ser definida a partir da "interioridade" total da estrutura da experiência, contemplando as relações polares desta. Entendida dessa maneira, a endogeneidade abrange um lato leque de fenômenos, que vão desde as fases da maturação (por exemplo, climatério e senescência, quando se é transformada toda a articulação da consciência com o mundo) até o conjunto das chamadas reações da estrutura da consciência. Como toda reação já é de antemão dada pelo estilo desta estrutura, não faz sentido se falar em uma reação em sentido exclusivo, já que tudo que mobiliza a consciência será sempre compreensível-endógeno. Desse modo, a noção de psicose reativa não deixa de ser em princípio endógena, embora não se defina integralmente como tal, pelo que veremos abaixo.

Cabe-nos agora determinar o campo dos transtornos psicóticos endógenos, que pode ser feito por meio de três índices:

A. em termos de seu início, a psicose endógena é aquela que surge por uma desestruturação dessa articulação primordial. Por exemplo, a esquizofrenia, que surge quando as relações habituais da estrutura da consciência com o mundo se transformam com o advento da adolescência e não conseguem atingir um novo equilíbrio. Para que haja essa desestruturação, é necessário que as relações de conexão anteriores à eclosão do transtorno estejam em relação de compreensividade até o momento dessa eclosão, o que inclui as chamadas psicoses reativas, nas quais esse fator é mais evidente, e que a lesão se dê nessa zona de ligação com o mundo. Não é determinante para essa definição se o ímpeto primordial dessa desarticulação venha do polo imanente, ou seja, das profundezas da estrutura da consciência, ou do polo trasncendente, ou seja, das efetividades do mundo relacional. Mas é fundamental que o polo dual histórico de relação seja transformado: ele é a raiz mais sólida de manutenção do sentido da estrutura da consciência (Binswanger, 1957). 
B. em termos prospectivos, a psicose endógena é aquela na qual a própria característica da patologia impede a restruturação da articulação típica da estrutura. V.g., no caso das melancolias, o desarranjo do ciclo sono-vigília impede a sincronização da estrutura com o mundo natural ou social;

C. em termos da totalidade da estrutura vivida (para os propósitos deste artigo o termo é sinônimo de estrutura da consciência), a desarticulação desta estrutura com o mundo promove a autonomização de zonas da estrutura da consciência, configurando o caráter patológico, quando a lógica de sentido do indivíduo é substituída pela lógica da doença (Jaspers: a lógica da doença "takes its own course following its own independent laws". 1997, p. 384)

Duas questões importantes sobre as psicoses endógenas. Primeiramente, o indício de que nelas sempre as estruturas primordiais de sentido estão atacadas e, portanto, trata-se de transtornos graves. A exceção seria o caso das psicoses reativas que, do ponto de vista da psicopatologia fenomenológica, nada são senão formas brandas da patologia endógena (vide o caso Ilse de Binswanger, 1957).

Em segundo lugar, é importante frisar que, com o emprego do conceito de origem para adequadamente retratar as relações de conexão do campo endógeno, fica bastante enfraquecida em suas determinações a própria noção de conexão. Ou seja, embora algumas vezes se possa estabelecer um fator causal/motivacional imediato e final para a eclosão do transtorno, não devemos nos exceder na certeza afirmativa das relações de conexão no campo da compreensividade endógena. Por exemplo, podemos eventualmente identificar certa pressão social em um sensitivo que o faz inquieto e mesmo persecutório. No entanto, no caso da eclosão de uma psicose endógena, é difícil dizer taxativamente que a pressão tenha sido a causa ou motivo da patologia. Tais fatos podem ser o início ou origem do transtorno, mas não sua causa ou motivo. Origem contempla a noção de uma conexão interior complexa, ao passo que a causa e o motivo traduzem uma ação partes extra partes, mecânicas, das relações de conexão. O surgimento das patologias endógenas depende de fatores estruturais que transcendem à lógica facilitadora da conexão imediata (é observando isso que classicamente se definia endógeno como hereditário). Não se deve confundir a origem da psicose a partir de um canal de compreensividade - que se perderá depois - com o reconhecimento de sua causalidade ou motivo. Em suma, estamos ainda muito longe de um conhecimento universal e evidente das doenças psicóticas endógenas, embora a sua existência seja notória. 
A exogeneidade. Esta se define por exclusão. Todo fenômeno psicótico cuja origem se dá fora da região de articulação primordial da estrutura da consciência com o mundo e que não comprometa a integridade do sentido dado na relação interpessoal dual é exógeno. A rigor, essa definição geral abrange todos os fenômenos, normais e patológicos, originados dessa "exterioridade". O exemplo mais notório é a embriaguez. Nesta, ocorre uma alteração do estado global da consciência que não tem como causa as formas habituais de sentido da sua estrutura. Pelo contrário, o sentido desta apenas recebe uma coloração quantitativa a partir da emergência exógena. Por exemplo, estando bem ou mal psicologicamente, se nos embriagarmos haverá alguma alteração de nosso estado de consciência. $O$ vetor deste é matizado pelo bem-estar ou mal-estar geral de nosso ânimo. Outro exemplo é a TPM, causalmente impingida à consciência, mas por ela matizada. A exogeneidade efetivamente brota de fora dessa articulação primordial, como definiram os clássicos, embora jamais de modo purificado e independente dela.

Podemos, portanto, defender, por meio da exogeneidade, uma causalidade mecânica, exterior à estrutura vivida, mas jamais uma causalidade independente, pois mesmo as causas cerebralmente determináveis, como tumores cerebrais ou demências, são matizadas por essa estrutura. Assim sendo, é nuclear para a noção de psicose exógena que, com exceção do momento agudo da alteração, não haja uma transformação do sentido global de uma consciência histórica ou, mais detalhadamente, que o sentido global dessa estrutura vivida permaneça reconhecível em seus perfis de relevância e significação dentro de certos limites da ação exógena (Binder, 1979) ou após o término de sua atividade.

No âmbito prático, deve-se mesmo dizer que, diante de uma patologia aguda, raramente se pode estabelecer um diagnóstico diferencial seguro entre ambas, embora algumas indicações possam ser sugeridas. Como a psicose exógena não modifica o sentido global da articulação da estrutura com o mundo e esse se dá por meio da experiência de significação, sobretudo a interhumana dual, temos que as psicoses exógenas tendem a assumir feições alucinatórias, com vivências ou conteúdos indefinidos ou frouxamente articulados. O delirium tremens é um caso radical disso, no qual as vivências aterrorizantes provêm menos de uma perda de significação do real do que de uma fantasmagoricização desse real por excesso de significação. 


\section{As relações entre psicoses endógenas e exógenas}

Mas se agudamente as psicoses exógenas nem sempre são determináveis, podemos, por outro lado, procurar rastrear sua progressão que, frequentemente, passa por um início endógeno e atinge a forma de exogeneidade apenas em seu apogeu. A evolução das paranoias transitórias dos cocainômanos é exemplo disso. Nascem de um excesso de aproximação exogenamente determinado - com a realidade, que geralmente preserva as linhas de significação da estrutura biográfica (p.ex. são as figuras familiares ou elementos da sociedade, como a polícia, os responsáveis pela perseguição). Com o passar do tempo e da toxicomania, não apenas essas paranoias surgem mais rapidamente diante da intoxicação, como podem surgir experiências alucinatórias puras, como visões de animais, sensação de animais na pele ou vozes anônimas. Nesse ponto, já podemos dizer tratar-se de uma condição exógena, sendo que muita vezes o paciente é capaz de relatar a própria experiência como patológica, o que é indicativo de preservação de sentido.

Por outro lado, em casos agudos ou transitórios nos quais o que está em jogo é uma ressignificação do mundo, não se pode conjecturar uma psicose exógena. Casos de psicóticos leves representam essa condição.

Embora as psicoses exógenas sejam causadas por uma diversidade de fatores, o mais relevante deles para a psiquiatria é a embriaguez, já que a maioria das situações fora esta são doenças somáticas que exigem tratamento e cura. Contrariamente, a embriaguez se liga a hábitos, muitas vezes, colidindo com a necessidade de supressão e cura.

Como dito acima, de modo algum se pode satisfazer, em um modelo monista, com um entedimento estanque, separado, do campo endógeno em relação ao exógeno. Mais importante do que reconhecer a existência de ambos é estabelecer nos casos particulares sua interrelação.

Opostamente ao exemplo do cocainômano, uma psicose exógena pode transformar-se em endógena, mesmo se, no seu início, não responder a nenhum dos itens definidores da endogeneidade. Exemplo típico dessa situação é o abusador de cannabis. Este tem uma alteração de seu estado de consciência toda vez que se embriaga, alterações em muitas situações compatíveis com quadros psicóticos sobretudo de modificação perceptual. No entanto, esse estado, mesmo se não repetido, pode evoluir para a perda do sentido dado na compreensividade quando, por definição, torna-se uma psicose endógena. 
Uma psicose endógena pode sofrer episódios de eventos psicóticos exógenos que, a princípio, constituem alterações da própria psicose que não seguem a sua lógica patológica interna. Casos típicos disso são as psicoses exógenas surgindo em esquizofrênicos que abusam de cannabis. A piora do quadro pode ter um componente agudo majoritariamente exógeno que, em certo número de vezes, podem ampliar a patologia endógena de base.

As alterações exógenas da estrutura da consciência podem ser assimiladas por esta, traçando um perfil de desenvolvimento anômalo da personalidade, cujo exemplo mais usual são os desenvolvimentos atípicos dos toxicômanos. Isso pode ocorrer em simultaneidade com alguma psicose endógena crônica, desenhando quadros clínicos complexos que apenas no limite permitem a distinção de suas origens.

Tendo em vista esses exemplos e a sua ampla ocorrência na clínica, devemos modificar o sentido da noção de exogeneidade, que vem sendo concebido, dadas suas raízes dualistas, de modo exageradamente independente. Melhor faríamos se, em lugar de psicose exógena, empregássemos a ideia de influxos exógenos ou ocorrências exógenas sobre a estrutura da consciência. Toda estrutura recebe participações exteriores a ela que tendem à assimilação pela sua lógica interna de sentido. Essas participações, exógenas por definição, são causas no sentido mecanicista da palavra; no entanto, insuficientes para explicar a totalidade do quadro clínico. Esses influxos são modulados pela estrutura e também podem, desde fora, modificarem-na. Contudo, serão sempre secundários e entendidos de maneira deflacionária em relação a essa totalidade. Apenas em raros casos se atinge verdadeiramente uma psicose exógena, ao passo que os influxos ocorrem cotidianamente. Assim, pode-se dizer que raramente a causalidade mecânica é fator suficiente para a eclosão da patologia. Na maior parte das vezes, ele é um fator apenas necessário dentro de uma constelação situacional da estrutura da consciência.

\section{Conclusões}

A divisão entre psicoses endógenas e exógenas é pertinente em uma concepção monista de psicopatologia, embora com limitações e grande asssimetria de importância entre os termos. Sua demarcação é dada pela identificação da estrutura global de sentido da implantação da consciência no mundo. Os transtornos endógenos são, portanto, ontologicamente anteriores aos exógenos e o seu tratamento exige um conhecimento minucioso das 
condições especiais do estilo do indivíduo ou do tipo de personalidade. Um transtorno de caráter endógeno revela ao mesmo tempo que um ponto importante da estrutura da consciência foi atacado e que a linha de compreensividade da biografia foi transformada. As psicoses exógenas são privativas, ou seja, definidas a partir da impossibilidade de identificação de uma origem endógena e sempre devem ser entendidas em relação à estrutura global da consciência. A aplicação da distinção endógeno-exógeno pode ser expandida para além do campo das psicoses, sendo que o melhor uso da noção de exogeneidade seria a partir da ideia de influxos ou ocorrências exógenas. $\mathrm{O}$ diagnóstico de psicose exógena não pode ser efetuado fora do exame particular das estruturas típicas ou individuais. Por fim, deve-se mencionar que a divisão endógeno-exógeno não se identifica com a divisão somático-não somático, ou seja, mesmo se estabelecermos uma base somática sólida para as doenças ditas endógenas, elas continuarão a ser entendidas como tal do ponto de vista de origem e características e mesmo uma psicose com origem somática determinada pode ser, fenomenologicamente, endógena, como a demência, por exemplo.

\section{Referências bibliográficas}

Binder H. (1979) Über alkoholische Rauschzustände. In: Bash K, editor. Ausgewählte Arbeiten. Band I: Klinische Psychiatrie. Bern-Stuttgart-Wien: Verlag Hans Huber. pp. 166-220.

Binswanger L. (1957). Schizophrenie. Pfullinger: Günther Neske Verlag.

Bleuler E. (1983). Lehrbuch der Psychiatrie. Berlim-Heidelberg-Nova York:Springer Verlag. $15^{a}$ edição.

Bonhoeffer K. (1912). Zur Frage des exogenen Psychosen. Neur. Zll.

Buytendilk F. (1967). Prolegomena einer Anthropologischen Physiologie. Salzburg: Otto Müller Verlag.

Goldstein K. (1951). La structure de l'organisme. Introduction à la biologie à partir de la pathologie humaine. Paris: Gallimard.

Jaspers K. (1997). General Psychopathology. Baltimore: The Johns Hopkins University Press.

Kretschmer E. (1975). Medizinische Psychologie. Stuttgart: Georg Thieme Verlag, 14 edição. 
Minkowski E. (1999). Traité de psychopathologie. Le Plessis-Robinson:Institut Synthélabo.

Parnas J. \& Bovet P. (1995) Research in psychopathology: epistemological issues. Compr. Psychiatry, 36 (3), 167-81.

Schneider K. (1953). Über die Grenzen der Psychologiesierung. Der Nervenarzt, v.3, 7-8. 15a edição.

(2007) Klinische Psychopathologie. Stuttgart: Georg Thieme Verlag,

Tellenbach H. (1983) Melancholie. Problemgeschichte. Endogenität. Typologie.

Pathogenese. Klinic. Berlim-Heidelberg-NovaYork-Tokyo: Springer Verlag. 4a edição. 